efforts to adjust the traction, the handles are carried backwards, straining the pressure, or altering the position of the blades; the command over the head is lessened; and not unfrequently, when the strain is great, the forceps slip.

Another means of correcting the defects of the ordinary forceps is to give to the handles a curve complementary to that in the blades, as in Aveling's forceps. This, however, only restores the line of simple traction to that of the axis of prehension. It does not meet the fourth requirement described above, of affording the means of varying the line of traction without straining or otherwise disturbing the grasp apon the head.

With all forceps which, when applied, form, so to speak, a rigid rod, the line of simple traction can be varied only by altering the position of the blades, or moving blades and head together. A change in the position of the blades does not necessarily imply diminished command over the head, yet in some cases this must undoubtedly happen. With the other resource, that of turning the head with the blades, the movement may occasionally bo advisable, but generally it would certainly derange the mechanism of the labour. It is important, therefore, that we should have at our command, when resistance is great, some other means of adjusting the line of traction, other than that supplied by the handles of the instrument. This means for facility and accuracy in the adjustment must be movable upon, and not a component part of, the rigid instrument. The requirement is met by adding a separate traction-rod, freely movable upon the forceps proper.

All the forms of traction-rods which have as yet been devised are open to the serious objection that they greatly complicate the instrument ; some simpler means is most desirable; and it would be 2 further recommendaton if it could be applied to any form of the forceps, and be used or laid aside as desired. This, I would suggest, is to be found in a simple hook, such as is here figured (Fig. 2). What I

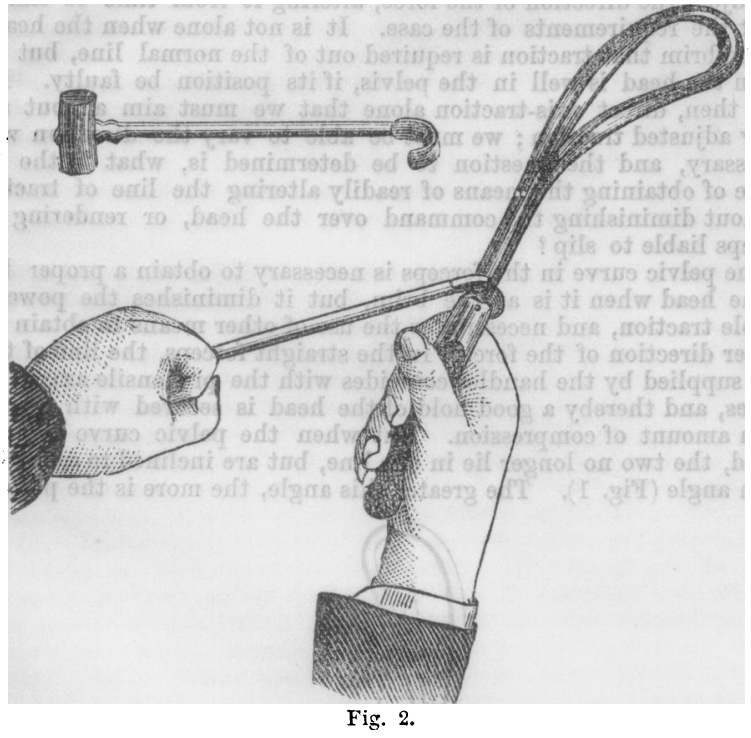

first employed was the ordinary crotchet and blunt hook combined, using the crotchet end as the hook, and it answered very well. Held in tho loft hand, the tractor can, when wanted, be attached between the shanks and over the lock. With it so placed, and the right hand grasping the handles in the ordinary manner, traction is made simultaneously with both hands, the right acting in the line of the handles, the left at a proper angle, so that the resultant will coincide with the line of the desired movement. The force can be thus exerted in any direction, and changed at any time, without affecting the hold of the instrument, or throwing a strain other than direct traction upon the foetal head. Perfect facility in the most delicate modification in the direction of the force is thus secured; simple traction without strain alone is used, whilst the means is simplicity itself, and can be used with any forceps. It is, I contend, a great mistake to relinqnish the hold of the prehensile handles, as recommended by Tarnier and his followers. We thus lose much of the valuable information which is conveyed through the instrument to the mind of the operator-that skilled tactus, the full value of which can be estimated by those only tho possess it.
An objection may be advanced that the power is applied less directly than with Tarnier's rods, and therefore there is loss of force. Even if this be the case, it is certainly largely counterbalanced by the gain in simplicity. And, after all, does not this suggestion look very like what has before been advanced? It embodies the action to which many have recourse, when they use both hands with the forceps; but it defines more clearly the principle, and gives greater precision to the action. It recalls to mind the fillet over the lock, suggested by H. F. Nägele, in 1843 ; and the peculiar instrument of Herman, with a similar application. ${ }^{1}$ But the idea associated with these is what I would wholly discard-that of leverage; whereas what is sought for and specially insisted upon, in the use of the simple tractor, is direct traction only.

The chief question is, Does the plan fulfil the end in view ? I have now used it in several difficult forceps cases, and am satisfied that obtained with the simple tractor the same advantage I had found from using a modified Tarnier's forceps. In one case I have had the opportunity of comparing the two methods with the same patient and therefore as near as possible under the same conditions. The first time, I employed the late Dr. Macdonald's modification of Tarnier's forceps, the second, the ordinary Simpson's forceps with the hook tractor; the latter anskered in every way as satisfactorily as the more complicated instrument. Those of my friends who have tried the tractor have reported favourably upon it. Experience alone will deeide the relative merits, with the sure result of the "survival of the fittest."

\section{A CASE OF RUPTURE OF THE SPLEEN.}

BY C. E. FAUNCE, M.R.C.S.ENG., Surgeon, $A r m y$ Medical Staff.

JoHs D., aged 25, a private in the 2nd Battalion Northumberland Fusiliers, was brought to the Station Hospital, Meean Meer, on March 30th, 1886, having been found dead in his bed that morning, at a camp about three miles away. He was on the road to the hills for his health. From evidence given at a court of inquiry held, with reference to the death of J. D., the following facts were elicited as to his condition up to the time he was last seen alive. A comrade who went out with him, on March 29th, at 7.45 P.M., to the head-quarter canteen, stated that on the way thither deceased fell heavily on to his left side, into a drain, but he only complained of having hurt his "shins," and went on to the canteen where they had some beer. Returning to the camp, deceased again fell, but rose all right, and said "good-night" to his companion.

At 10 oclock P.M., he was found lying near a tent, by a sergeant, who, with the help of another man, took him to his tent and put him to bed. At 3 A.M., a comrade who was sleeping in the same tent woke up and found the deceased "creeping about" saying that he wanted "to go to the rear;" but when he tried to take him thither he refused to go; he therefore put him back to bed again, and the next time he saw him, he was dead-he was found dead in his bed at $5 \mathrm{~A}$.M.

Although the man was stated to have been sober, he had evidently been drinking a good deal without becoming absolutely drunk. He had served in India for six years, and during that time had been five times in hospital for ague ; and it was on account of his debility from malaria that he was being sent to the hills.

Post mortem Examination, made about Four Hours after Death.There were no marks of external violence, except a recent looking bruise, about two inches long, over the crest of the ilium. On opening the abdomen, a large quantity of dark-coloured blood escaped, measuring two pints. The peritoneum was normal in appearance, and the intestines did not show any signs of injury or congestion. The stomach was empty, and no odour of alcohol was detected. On removing the intestines and examining the cavity of the abdomen, the spleen was felt to be ruptured, with a number of large blood-clots lying in its vicinity. This rupture extended along the whole convex surface of the organ, and at its lower part right through its substance. The spleen weighed 22 ounces, was very congested, and extremely friable. The liver weighed 52 ounces; it was pigmented and con. gested, but its substance was firm. All the other organs were healthy.

Testimonial to Dr. Herbert Birmingham.-Dr. Birmingham, late medical officer of Castlebar Dispensary, on the eve of his departure to Australia, was last week presented with an address by his numerous friends of Ballinrobe. The address was accompanied by a valuable set of surgical instruments. 